\title{
Townes-Brocks syndrome
}

\author{
INSERM
}

\section{Source}

INSERM. (1999). Orphanet: an online rare disease and orphan drug data base. TownesBrocks syndrome. ORPHA:857

Townes-Brocks syndrome (TBS) is a rare genetic disorder characterized by the triad of imperforate anus, dysplastic ears often associated with sensorineural and/or conductive hearing impairment, and thumb malformations. These features are often associated with other signs mainly affecting the kidneys and heart. 